\title{
Mechanical Properties and Microstructures of Locally Produced Aluminium-Bronze Alloy
}

\author{
Uyime Donatus ${ }^{1}$, Joseph Ajibade Omotoyinbo ${ }^{1}$, Itopa Monday Momoh ${ }^{1,2}$ \\ ${ }^{1}$ Department of Metallurgical and Materials Engineering, Federal University of Technology, Akure, Nigeria \\ ${ }^{2}$ Engineering Materials Development Institute, Akure, Nigeria \\ Email: rhodave2011@gmail,com
}

Received June 4, 2012; revised July 12, 2012; accepted July 24, 2012

\begin{abstract}
This work studied the feasibility of producing a dual-phase aluminium bronze alloy and the use of selected treatments to manipulate the mechanical properties of the produced alloy using local techniques, as a potential replacement for conventional structural materials, particularly steels. Sand casting was used and was found to be effective based on its advantages of low cost, ease of use and flexibility in the production of a dual-phase aluminium bronze alloy with pre-selected composition of $11 \% \mathrm{Al}$ content. Cold deformation of 10 and $20 \%$ degrees and selected heat treatments were used on the cast alloy to influence its mechanical properties. The selected heat treatments are solution heat treatment, normalising, and ageing. The results showed that normalising gave the optimum mix of tested mechanical properties with ultimate tensile strength in the range of $325 \mathrm{MPa}$, elongation of around $60 \%$ and Rockwell hardness values of 46.5 - 63.7 HRc, making this alloy suitable as alternatives to steel in low/medium strength structural applications.
\end{abstract}

Keywords: Aluminium-Bronze; Solution Heat Treatment; Dual-Phase; Cold Deformation

\section{Introduction}

Aluminium bronzes are copper based alloys with aluminium as the major alloying element usually in the range 5\% - 14\% compositionally in the alloy, other alloying elements sometimes intentionally introduced are iron, nickel, manganese, silicon and tin depending on the intended application of the aluminium bronze.

Aluminium bronzes give a mix of a chemo-mechanical properties superseding many other alloy series. These make them to be most preferred particularly for demanding applications [1]. "Aluminium bronzes are most valued for their high strength and corrosion resistance in a wide range of aggressive media" [2]. "They are most commonly used in applications where their resistance to corrosion makes them preferable to other engineering materials. Another notable property of aluminium bronzes are their biostatic effects. The basic properties of copper alloys are largely influenced by copper itself" [3]. The copper component of the alloy prevents colonization of marine organisms including algae, lichens, barnacles and mussels, and therefore can be preferable to stainless steel or other non-cupric alloys in applications where such colonization would be unwanted.

Besides their strength, toughness, corrosion resistance in a wide range of aggressive media, wear resistance, low magnetic permeability, non-sparking characteristics, aluminium-bronzes can be readily cast, fabricated, and ma- chined. They can also be readily welded in either cast or wrought form $[4,5]$.

In spite of these wonderful attributes posed by aluminium bronzes, it is surprising to know that not much work have been done on aluminium bronzes in Africa especially in Nigeria. Structural applications are mostly based on ferrous materials, steels in particular. Findings have shown that aluminium bronzes are fast replacing contemporary steel materials for some specific applications especially in components for marine/sub-sea applications. The consumption of aluminium bronzes have increased sharply in the USA. And other countries due to their property of being non-rusting in marine environment as well as also their resistance to corrosion in highly aggressive environments. Aluminium bronze alloy construction for basic oxygen and electric arc furnace hoods, roofs and side vents was identified as a viable alternative for carbon steel construction for these equipments. The use of aluminium alloy was found to be as much as five times the life of comparable carbon steel [6]. Manganese-nickel-aluminium-bronze (Aqualloy), for example, was found to be more efficient than stainless steel in making propellers. Nickel-aluminium bronzes have greater resistance to cavitation erosion than cast steel, Monel alloys and the 400 and 300 series of stainless steels, that is why it is suitable for propellers, pump impellers and casings and turbine runners giving them long 
service lives and operating efficiency [7]. Aluminium bronze wire is almost as strong as good steel wire and castings made from it are almost as hard as steely iron [8].

There are various categorizations of aluminium bronzes, $90 \%$ of them by different authors and bodies do not leave out the duplex phase group of aluminium bronzes which is the primary focus of this research. The dual (duplex) phase represents the highest tonnage and most alloyed of the aluminium bronzes, containing $8 \%-11 \%$ aluminium and usually with the additions of iron and nickel for higher strength [9] and for prevention or delay of $\beta$ solid solution decomposition to the $\left(\alpha+\gamma_{2}\right)$ eutectoid, $\gamma_{2}$ is undesirable and causes brittleness; slow cooling brittleness$3 \%$ iron and 3\% nickel were considered most suitable [10]. This dual phase aluminium bronzes can be worked or heat treated to obtain optimal strength and ductility [11]. During equilibrium cooling of aluminium bronze alloy with $10 \%$ aluminium, $\alpha$-aluminium bronze precipitates from $\beta$-aluminium bronze phases below $930^{\circ} \mathrm{C}$ [12].

In marine environment, the requirements for marine component are, among others, high strength to weight ratio, good castability, and tolerance of local working for repairing damage sustained during service which narrow our choice of alloy to aluminium bronzes. Which thus serves as our basis for this research work: to develop a ( $\alpha$ $+\beta) /\left(\alpha+\gamma_{2}\right)$ phase aluminium bronze with a view to seeking replacement for conventionally used components that fail readily during service.

\section{Materials and Equipments}

Copper coils, aluminium scraps, weighing balance, pit furnace, rolling machine, vernier calliper, bench vice, student lathe machine, grinding and polishing machine, hack-saw, muffle furnace, metallurgical microscope, digital Rockwell tester, Mosanto tensometer.

\subsection{Experimental Procedures}

\subsubsection{Production}

$1 \mathrm{~m}$ long and $10 \mathrm{~mm}$ in diameter aluminium bronze rods of composition as given in Table 1 were produced via sand casting by dissolving a measured amount of the aluminium piece in a measured molten copper in a fired pit furnace, stirred and cast. The chemical analysis of the produced aluminium bronze alloy was evaluated using a mass spectrometer. The cast aluminium bronze rods where subjected to $10 \%$ and $20 \%$ cold deformation using a miniature rolling machine.

\subsubsection{Heat Treatment}

The deformed rods where then subjected to selected forms of heat treatment: annealing, quenching (solution heat treatment), normalizing and ageing using a muffle
Table 1. Chemical composition of aluminium bronze developed.

\begin{tabular}{cc}
\hline Element & \% Weight \\
\hline $\mathrm{Cu}$ & 89.0764 \\
$\mathrm{Al}$ & 10.8230 \\
$\mathrm{Si}$ & 0.0495 \\
$\mathrm{Fe}$ & 0.0242 \\
$\mathrm{Mg}$ & 0.0150 \\
$\mathrm{Zn}$ & 0.0019 \\
\hline
\end{tabular}

furnace. The normalising (heating to $250^{\circ} \mathrm{C}$ and cooling in air) and ageing (heating to $160^{\circ} \mathrm{C}$ and $180^{\circ} \mathrm{C}$, held for 6 hours and then cooled in water at room temperature) were done on prior annealed and solution heat treated samples. Annealing was done on prior deformed rods by heating to $750^{\circ} \mathrm{C}$ and holding for 2 hours followed by cooling in the furnace while solution heat treatment was carried out by heating the samples to $900^{\circ} \mathrm{C}$ and holding for 15 minutes before cooling in chilled water. Several samples were selected per treatment.

\subsubsection{Tensile and Hardness Test}

The heat treated rods where then machined to tensile standard configuration test which was conducted in a Mosanto Tensometer. The dimension used is as shown in Figure 1. The hardness tests were carried out on a Digital Rockwell Tester by applying a force of $60 \mathrm{Kgf}$ (about $588 \mathrm{~N}$ ). Prior to this, the specimens were grinded to a flat surface using an emery paper of varios grits (between 60 to 180 micron)

\subsubsection{Micro-Examination}

A daheng software driven optical microscope was used to analyzed the microstructures of the developed alloy. Prior to this, the specimen for the microscopy were mounted, grinded using a series of emery paper of grits sizes ranging from $60 \mu \mathrm{m}-2400 \mu \mathrm{m}$, it was further polished using an ultrafine polishing cloth, its effectiveness was enhanced using polycrystalline diamond suspension of particle size $3 \mu \mathrm{m}$ with ethanol solvent. The specimen was chemically etched by swabbing using acidified ferric chloride composing of $8 \mathrm{~g}$ of Ferric (II) Chloride, 50mil of $\mathrm{HCl}$ and 100 mil of water for 60 seconds before microstructural examination was performed using optical microscope.

\section{Results and Discussion}

\subsection{Casting}

Despite the difficulties encountered that would have be a barrier in the course of casting, sand casting was selected as a the best means of casting locally based on the available materials, low cost and flexibility; it was found ef- 


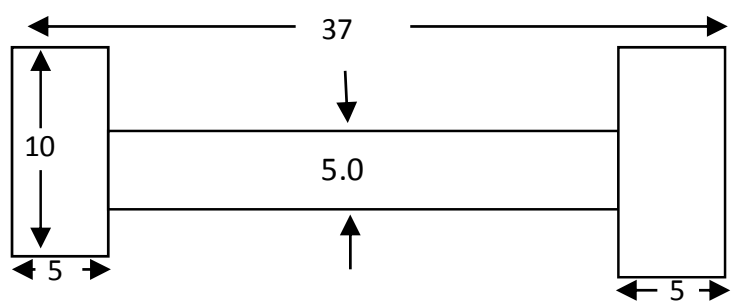

Figure 1. A sketch of standard tensile specimen (all dimensions in $\mathbf{m m}$ ) [13].

fective as a sound golden yellow dual-phase aluminium bronze alloy with a density of $7.74 \mathrm{~g} / \mathrm{cm}^{3}$ and composition as shown in Table $\mathbf{1}$ was produced.

\subsection{Mechanical Properties of As-Cast Aluminium Bronze Alloy Produced}

The mechanical properties of the as-cast aluminium bronze sample with $0 \%$ deformation and no heat treatment are as shown in Figure 2(a) with its ultimate tensile strength being $230.4 \mathrm{MPa}$ (low), very high hardness of $38.4 \mathrm{Rc}$ and low ductility of $11.2 \%$ elongation. This could be attributed to the presence of sparse distribution of suspected $\alpha$ precipitates in a predominant $\beta$ ' matrix which has high strength (hardness) and low ductility [14] as can be seen in its microstructure in Plate 1. However, this is not to say that this as-cast structure cannot be used for some important engineering applications where loads of magnitudes in the range of one-third of its UTS are being used.

\subsection{Effect of Solution Heat Treatment on the Mechanical Properties of Aluminium Bronze}

This treatment significantly improved the tensile properties of this alloy (Figure 2(b)) particularly in the 20\% deformation sample as compared to the as-cast structure though with significant reduction in hardness. This was probably due to the transformation of the $\beta$ '-phase present in the ascast structure to produce structures of aluminium bronze pearlite $\left(\alpha+\gamma_{2}\right)$ in a matrix of $\alpha$ dominance, this structure has no clear area of stress concentration but rather has lamellar or alternate layers of $\gamma_{2}$ and $\alpha$ with the latter predominating the structure. See Plates 2 and 3. The soft $\alpha$ phase, serving as the major matrix for the aluminium bronze pearlite, possibly brought about the improved tensile strength and ductility with signifycant reduction in hardness strength.

\subsection{Effect of Normalising on the Mechanical Properties of Solution Heat Treated Aluminium Bronze}

This produced more improved mechanical properties with the tensile strengths of both the 10 and $20 \%$ degrees of deformation (Figure 2(c))exceeding that of the SHT slightly and clearly higher than that of the as-cast structure, the hardness value for the $10 \%$ deformation sample was clearly greater than that of the SHT while that of the $20 \%$ degree of deformation ironically dropped below that of the SHT, but dropped far below that of the as-cast structure in both cases. The ductility as a measure of $\%$ elongation was significantly higher as compared to the as cast structure but just slightly greater than that of the SHT. The micrograph for the $10 \%$ degree of deformation (Plate 4), shows more dispersed precipitates of $\alpha$ in a more refined $\beta$ ' matrix with finer grain structure, more than that evident in that of the as-cast structure. The pearlite structure in the SHT has been altered, with the lamellar structure transforming to give $\beta$ ' with more precipitates of $\alpha$ (as compared to the as-cast structure) precipitating out from the $\beta$ ' phase into the same matrix with more of it at the grain boundaries and with no undesirable $\gamma_{2}$ phase, at all, which has deleterious effect on mechanical properties of aluminium bronze according to literatures. This probably produced the improved properties effect as compared to the SHT and as-cast structure except for the reduction in hardness strength when compared to that of the as-cast structure particularly. The micrographs of the $20 \%$ degree of deformation (Plate 5), however, show that the structure is entirely an aluminium-bronze pearlite plus $\gamma_{2}$ structure with the later being predominant, the presence of the aluminium bronze pearlite possibly accounted for the contrasting decline in its hardness value as compared to that of the SHT and as-cast structure.

\subsection{Effect of Ageing on the Mechanical Properties of Solution Heat Treated Aluminium Bronze}

Improved UTS in all cases (Figures 2(d) and (e))particularly as compared to the control specimen with the exception of N and SHT (20\% deformation) reduced hardness values in AG1 and AG2(10\% deformation) as compared to the control, SHT and N but AG2 (20\% deformation) showed improved hardness value only as compared to SHT, increased ductility in AG1(10\% deformation) and $\mathrm{AG} 2(20 \%$ deformation) as shown in figures 2(d) and (e) respectively - when compared to SHT, C and N; but reduced in AG1 and AG2 (both of 20\% deformation) only as compared to SHT and N. Ageing the alloy surprisingly produced enlarged plates of the $\alpha+\gamma_{2}$ aluminium bronze pearlite particularly for $20 \%$ deformation $-180^{\circ} \mathrm{C}$ samples (Plate 9), but spread over patches of possible kappa in $\alpha$ matrix for the $160^{\circ} \mathrm{C}$ samples (Plates 6 and 7) with fluctuating mechanical properties though never at any instant equal to or lesser than the mechanic- cal properties of the as-cast structure except for the hardness. It should also be noted that ageing at $180^{\circ} \mathrm{C}$ for 6 hours after $20 \%$ cold deformation and SHT gave the highest 


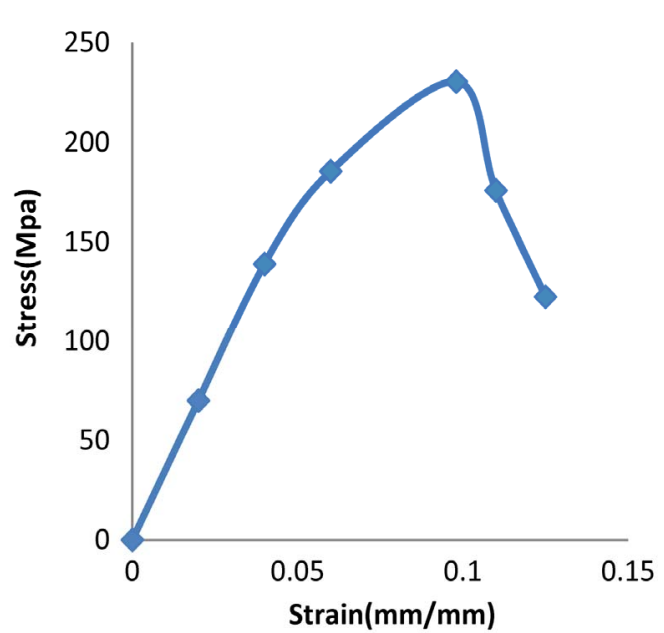

(a)

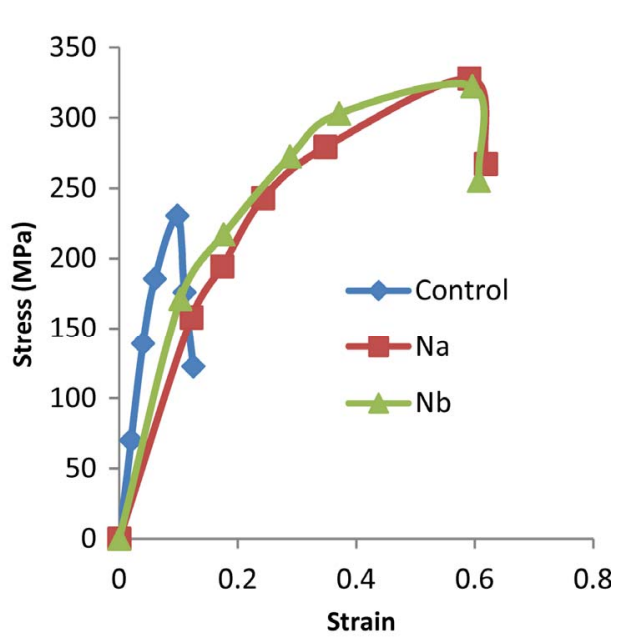

(c)

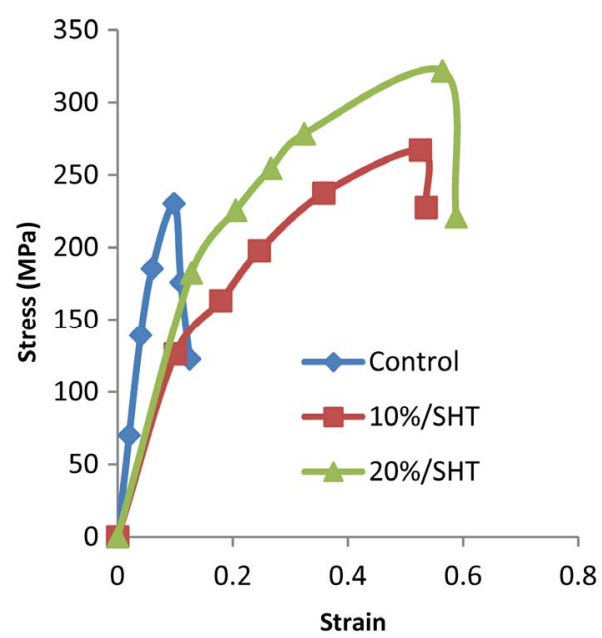

(b)

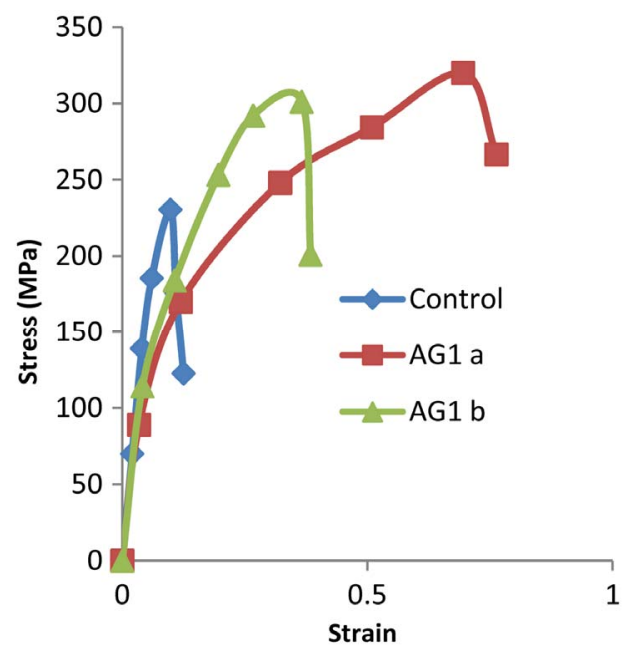

(d)

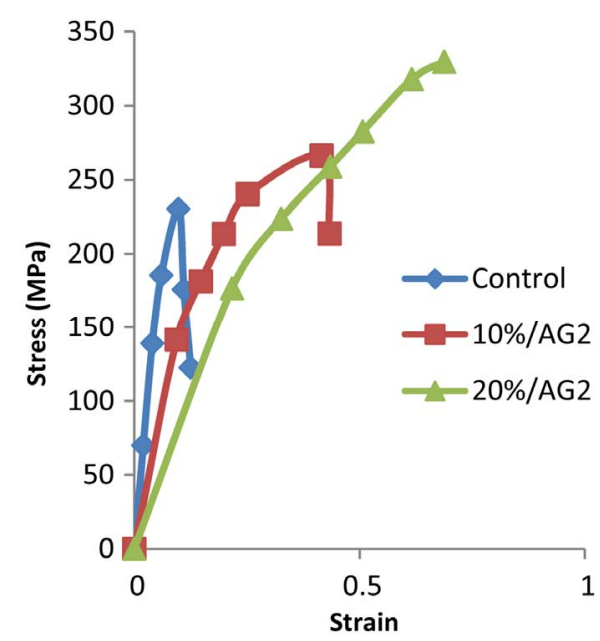

(e)

Figure 2. (a) Stress-Strain curve of as-cast Al-bronze sample (control-C); (b) Stress-Strain curve of cast Al-bronze subjected to cold deformation followed by solution heat treatment; (c) Stress-Strain curve of cast Al- bronze subjected to cold deformation followed by normalizing; (d) Stress-Strain curve of cast Al-bronze subjected to cold deformation followed by ageing at $160^{\circ} \mathrm{C}$ for 6 hours after solution heat treatment; (e) Stress-Strain curve of cast Al-bronze subjected to cold deformation followed by ageing at $180^{\circ} \mathrm{C}$ for 6 hours after solution heat treatment. 


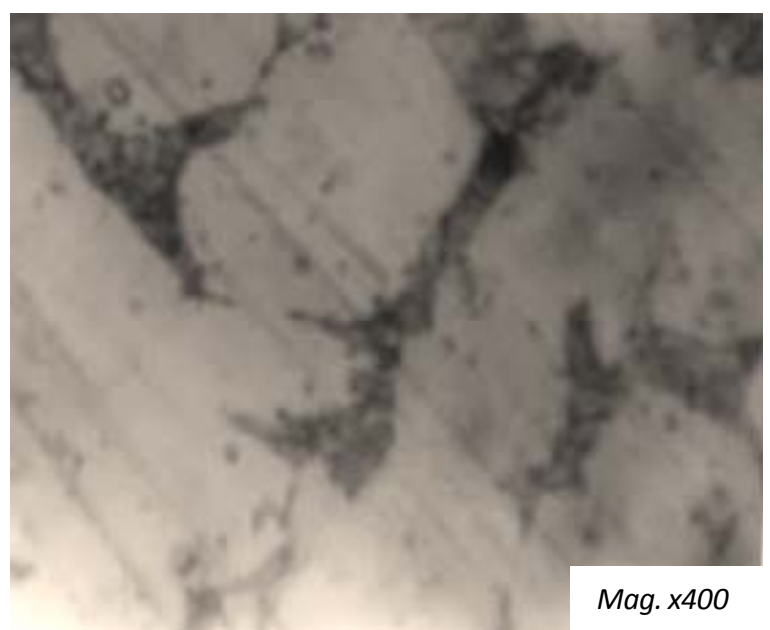

Plate 1. Microstructure of as-cast Aluminium bronze sample.



Plate 2. Microstructure of cast Al-Bronze sample subjected to $10 \%$ cold deformation followed by SHT.

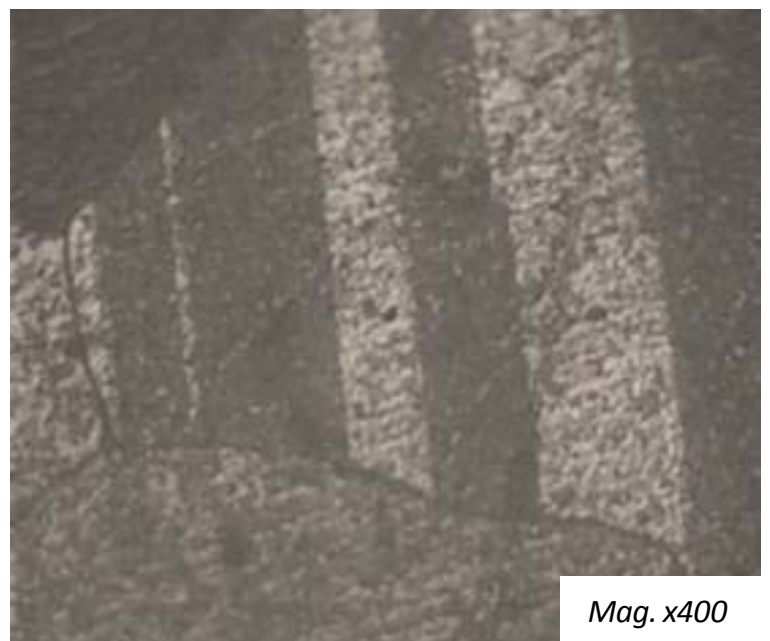

Plate 3. Microstructure of cast Al-Bronze subjected to $20 \%$ cold deformation followed by SHT.

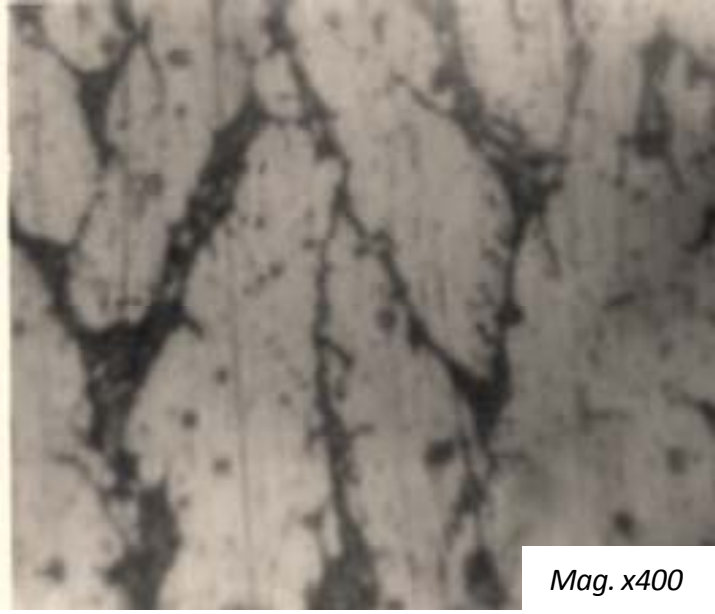

Plate 4. Microstructure of cast Al-bronze sample subjected to $10 \%$ deformation followed by SHT and Normalising.

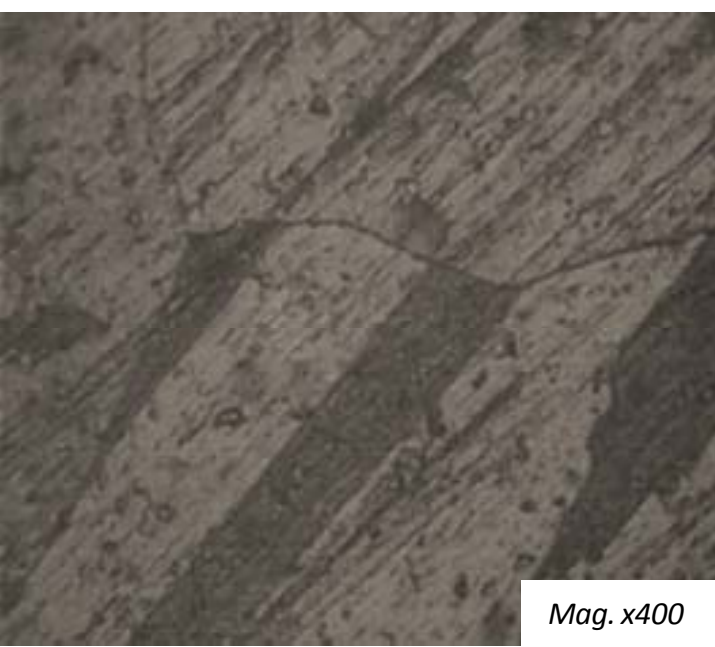

Plate 5. Microstructure of cast Al-bronze sample subjected to $20 \%$ deformation followed by SHT and Normalising.

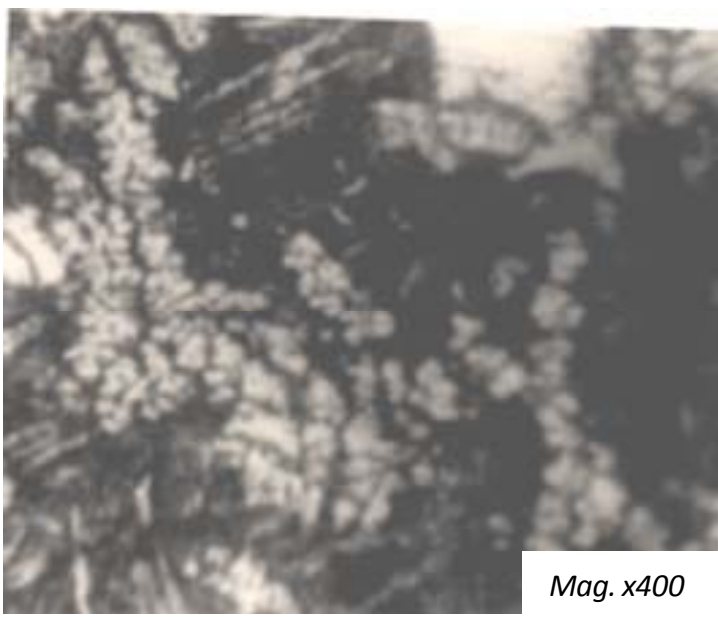

Plate 6. Microstructure of cast Al-Bronze sample subjected to $10 \%$ deformation followed by SHT and ageing at $160^{\circ} \mathrm{C}$ for 6 hours. 


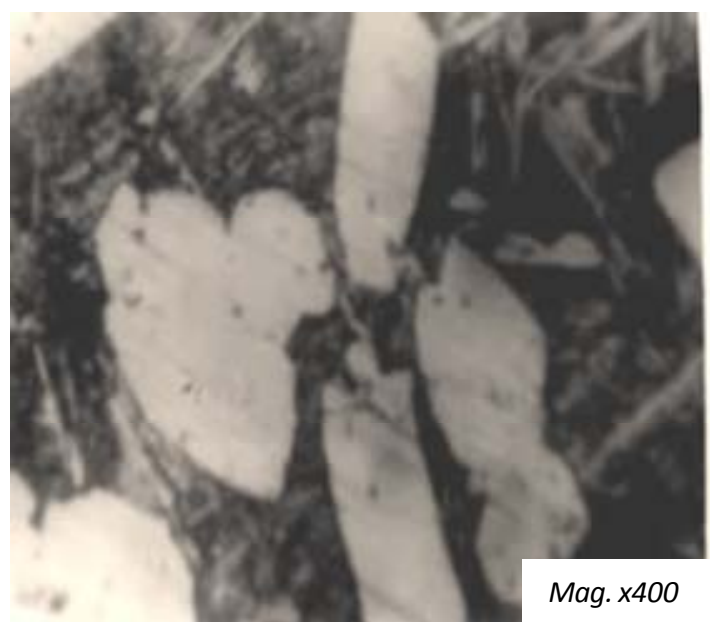

Plate 7. Microstructure of cast Al-Bronze sample subjected to $20 \%$ deformation followed by SHT and ageing at $160^{\circ} \mathrm{C}$ for 6 hours.

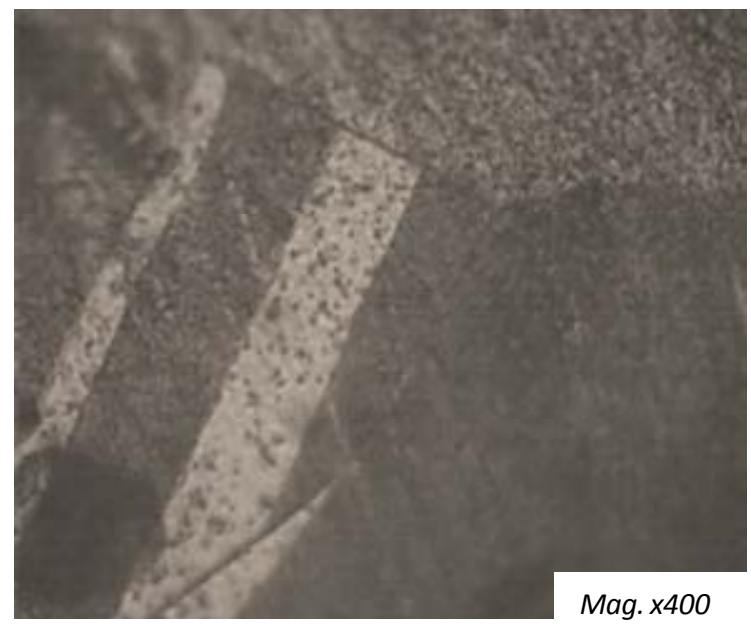

Plate 8. Microstructure of cast Al-Bronze sample subjected to $10 \%$ deformation followed by SHT and ageing at $180^{\circ} \mathrm{C}$ for 6 hours.

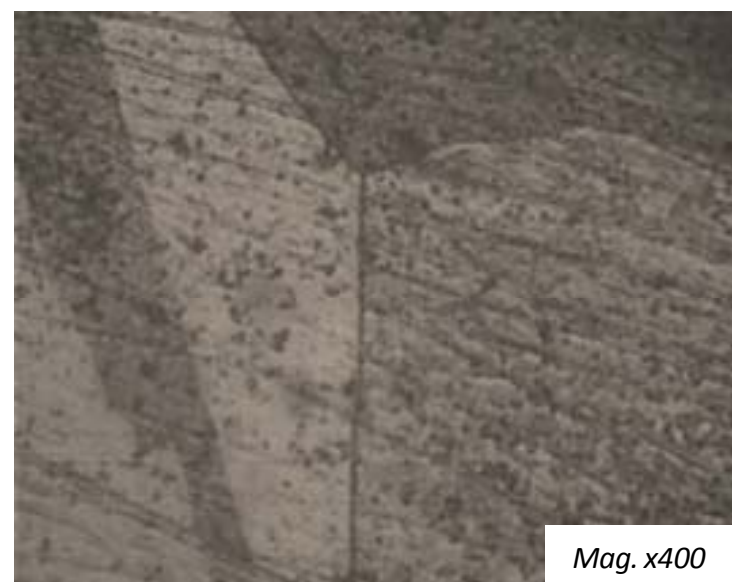

Plate 9. Microstructure of cast Al-Bronze sample subjected to $20 \%$ deformation followed by SHT and ageing at $180^{\circ} \mathrm{C}$ for 6 hours.
Table 2. Sumarry of the mechanical properties of the developed aluminium bronze alloy.

\begin{tabular}{ccccccccc}
\hline \multirow{2}{*}{ Treatments } & \multicolumn{2}{c}{$\begin{array}{c}\text { Proof stress } \\
(0.5 \% \mathrm{e}, \mathrm{MPa})\end{array}$} & \multicolumn{2}{c}{ UTS (MPa) } & \multicolumn{2}{c}{$\begin{array}{c}\text { Hardness } \\
(\mathrm{HRc})\end{array}$} & \multicolumn{2}{c}{$\begin{array}{c}\text { Elongation } \\
(\%)\end{array}$} \\
\cline { 2 - 10 } & $10 \%$ & $20 \%$ & $10 \%$ & $20 \%$ & $10 \%$ & $20 \%$ & $10 \%$ & $20 \%$ \\
\hline C & \multicolumn{2}{c}{169} & \multicolumn{2}{c}{230.4} & 38.4 & 11.2 \\
SHT & 125 & 185 & 267.2 & 321.8 & 49.8 & 51.3 & 53.4 & 58.7 \\
N & 165 & 175 & 327.9 & 322.4 & 63.7 & 46.5 & 60.9 & 60.7 \\
AG1 & 85 & 102 & 320.0 & 301.0 & 45.4 & 44.0 & 76.3 & 38.4 \\
AG2 & 148 & 173 & 266.3 & 329.6 & 39.9 & 53.4 & 43.5 & 68.8 \\
\hline
\end{tabular}

Key: $\mathrm{C}=$ as cast Al-Bronze sample with $0 \%$ deformation and no treatment, SHT $=$ Solution Heat Treated samples (heated to $900^{\circ} \mathrm{C}$ followed by quenching in chilled water), $\mathrm{N}=$ Samples normalised at $250^{\circ} \mathrm{C}$ for 20 minutes after SHT, AG1 $=$ Samples aged at $160^{\circ} \mathrm{C}$ for 6 hours after SHT, AG2 = Samples aged at $180^{\circ} \mathrm{C}$ for 6 hours after SHT.

value of tensile strength, good ductility as shown in Table 2 - probably because of the enlarged alternate plates of the $\alpha+\gamma_{2}$ in the entire pearlitic structure, \{though relatively low at the sample subjected to $10 \%$ deformation (Plate 8) $\}$ - and fair enough hardness value which was only lower than that of the ascast structure and the $10 \%$ degree of deformation samples normalised after SHT.

\section{Conclusion}

This research work has shown that aluminium bronze alloys with improved mechanical properties and microstructures as compared to conventionally used structural alloys can be produced locally. Sand casting was found effective-base on its advantages of low cost, ease of use and flexibility-in the local production of the dual-phase aluminium bronze with carefully selected composition of $11 \% \mathrm{Al}$ content. Of the selected heat treatments-after cold deformation of $10 \%$ and $20 \%$ degrees are: solution heat treatment (heating the cast alloy to $900^{\circ} \mathrm{C}$ and quenching in chilled water); normalising (heating some of the solution heat treated samples to $250^{\circ} \mathrm{C}$ soaking for 20 minutes and cooling in air); and ageing (heating some of the solution heat treated samples to $160^{\circ} \mathrm{C}$ and $180^{\circ} \mathrm{C}$ respectively and held for 6 hours at these temperatures before cooling in water), normalising gave the optimum mix of tested mechanical properties with ultimate tensile strength in the range of $325 \mathrm{MPa}$, elongation of around $60 \%$ and Rockwell hardness values of 46.5 - $63.7 \mathrm{HRc}$, making this alloy suitable as alternatives for low/medium strength level applications.

\section{REFERENCES}

[1] C. Vin, "Aluminium Bronzes Part I \& II. Metallurgy of Copper and Copper Alloys," Copper Development Association, 2002.

[2] J. A. Wharton, R. C. Barik, G. Kear, R. J. K. Wood, K. R. Stokes and F. C. Walsh, "The Corrosion of Nickel-Alu- 
minium Bronze in Seawater," Corrosion Science, Vol. 47, No. 12, 2005, pp. 3336-3367.

[3] D. N. J. William, "Metallurgy of Copper Based Alloys," Copper Development Association, Inc., 2010, pp. 1-3.

[4] Copper Development Association, "Aluminium Bronze Alloys for Industry," Copper Development Association publications, 1986.

[5] Copper Development Association, "Welding of Aluminium Bronzes," Copper Development Association publications, 1988.

[6] C. B. J. Lawrence and K. S. Vimod, "Aluminium Bronze Alloys to Improve the System Life of Basic Oxygen and Electric Arc Furnace Hoods, Roofs and Side Vents," Final Report, US Department of Energy (DOE), 2006. doi:10.2172/896794

[7] Copper Development Association, "Designing Aluminium Bronze Castings," Engineering, Vol. 223, No. 8, 1983, pp. 1-7.

[8] W. H. Norman, “Aluminium Bronze," Henley’s Twentieth Century Formulas Recipes Processes Encyclopedia, 2009, pp. 1-2.
[9] Copper Development Association, "Equilibrium Diagrams; Selected Copper Alloy Diagrams Illustrating the Major Types of Phase Transformations," Publication Number 94, 1992.

[10] K. Masao and U. Shoji, "The Structure of Copper-Aluminium-Nickel-Iron Quaternary Cast Alloys," Transactions of JIM, Vol. 1, No. 2, 1960, pp. 103-107.

[11] A. A. Hussein, "Structure-Property-Relationships in Dual Phase Cu-Al Alloys," Metallurgical and Materials Transactions A, Vol. 13, No. 5, 1982, pp. 837-846. doi:10.1017/CBO9780511810930.005

[12] G. Eli and B. Menachem "Phase Transformation in Permanent-Mould-Cast-Aluminium Bronze". Journal of Materials Science, Vol. 23, No. 10, 1988, pp. 3558-3562. doi:10.1007/BF00540495

[13] W. F. Horsford, "Mechanical Behaviour of Materials," Cambridge University Press, New York, 2005, pp. 39-67.

[14] D. R. Askeland and P. P. Phule, "The Science and Engineering of Materials," International Student Edition, Bill Stenquist, Nelson, 2006, pp. 514-515. 